\title{
ÖRNEK BİR YIĞMA BİNA ÜZERINNDE 1998, 2007 VE 2019 TÜRK DEPREM YÖNETMELİKLERININ KARŞILAŞTIRMALI OLARAK İRDELENMESİ
}

\author{
Aminullah AMANI*

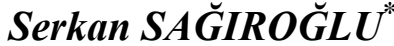 \\ Âdem DOĞANG $\breve{U} N^{*}$
}

Alınma: 31.07.2018; düzeltme: 31.08.2019 ; kabul: 07.01.2020

\begin{abstract}
Öz: Türkiye'de yığma yapılar halen en fazla olan yapı sistemlerinden biridir. Yığma yapılar son yıllarda özellikle şehir merkezlerinde pek fazla inşa edilmediğinden, sanki ikinci plana atılmış gibi görünse de yeni sistemlerin ömrü henüz tam olarak bilinmemektedir. Oysa yığma yapı sistemi binlerce yıldır uygulanmıştır. Bu nedenle gelecekte tekrar ön plana çıkma ihtimalleri bulunmaktadır. Yığma yapılarda düşey taşıyıcı elemanlar duvarlar olduğundan özellikle deprem gibi yatay yükler altında davranışları, geleneksel betonarme çerçeve sistemlerden oldukça farklıdır. Bu yüzden yığma yapılar deprem yönetmeliklerinde ya ayrı bir bölüm olarak yer almakta ya da bunlar için özel yönetmelikler hazırlanmaktadır. Ülkemizde yığma yapıların depreme göre hesap ve tasarımı konusunda yönetmeliklerde zaman içinde bazı değişiklikler olmuştur. 1998 yönetmeliği ile 2007 yönetmeliği arasında çok önemli farklar olmasa da, 2019 yönetmeliği önemli farklar içermektedir. Bu makalede ülkemizde uygulanmış olan 1998 ve 2007 yönetmelikleri ile 2019 yılından itibaren yürürlüğe girecek olan deprem yönetmeliği hükümleri örnek bir bina üzerinde karşılaştırılmalı olarak irdelenmektedir. 2019 da yürürlüğe girecek olan yönetmelikte başta deprem bölgesi ve zemin sınıfı gibi yığma yapıların hesap ve tasarımını etkileyen değişiklikler olmuştur. 2007 yönetmeliğine göre 1. Derece deprem bölgesi olan Bingöl'de olduğu varsayılan örnek bina üzerinden elde edilen sonuçlara göre, yeni 2019 yönetmeliğine göre hesaplanan taban kesme kuvveti 2007 yönetmeliğine göre hesaplanan değerden \%42, 1998 yönetmeliğine göre hesaplanan değerden ise \%77 daha büyük çıkmıştır.
\end{abstract}

Anahtar kelimeler: Deprem Yönetmeliği, Taban Kesme Kuvveti, Yığma Bina

\section{A Comparative Study on the Turkish Earthquake Codes of 1998, 2007 and 2019 on a Sample Masonry Building}

\begin{abstract}
In Turkey, masonry structures are still one of the most frequently used structural systems. Since masonry structures have not been built much in recent years, especially in city centers, it seems as they are not considered as a primary option, but the life of new systems is not yet known. However, the masonry building system has been applied for thousands of years. For this reason, there is a possibility that they come into prominence in the future. The behavior of masonry structures under horizontal loads, especially earthquakes, is quite different from that of conventional reinforced concrete frame systems, as vertical load-bearing elements are walls. Thus, masonry structures are either included in seismic codes as a separate section or special regulations about them are published.
\end{abstract}

* Uludă̆ Üniversitesi, Mühendislik Fakültesi, İnşaat Mühendisliği Bölümü, 16059, Bursa İletişim Yazarı: Serkan SAĞIROĞLU (serkansagiroglu@uludag.edu.tr) 
There have been some changes over time in the regulations regarding the calculation and design of masonry structures in our country. Although there are no significant differences between the 1998 and the 2007 seismic codes, the 2019 seismic code contains significant differences. In this paper, the provisions of the 1998, 2007 seismic codes along with those of the new seismic code that will come into force in 2019 are being compared and studied on a sample building. The seismic code, which will go into effect in 2019, has the changes such as earthquake region and local site class which affect the calculation and design of masonry structures. Based on the results obtained on the sample building assumed to be in Bingöl which is the $1^{\text {st }}$ degree earthquake region according to the 2007 code, the base shear force calculated according to the new 2019 code is $38 \%$ higher than the value calculated according to the 2007 code and $73 \%$ higher than the value calculated according to the 1998 code.

Keywords: Earthquake Code, Base Shear, Masonry Building

\section{GÍRIŞ}

Türkiye dünyanın en aktif ve tehlikeli deprem kuşaklarının birisinde bulunmaktadır. Türkiye'de nüfusun \%70'i 1 . ve 2 . derece deprem bölgelerinde yaşamakta ve mevcut yapıların \%90'dan fazlası deprem riski altında bulunmaktadır (Uğuz, 2016). Yaklaşık olarak her on yılda bir, yapısal hasarlara neden olan yıkıcı depremler meydana gelmekte ve binlerce kişi bu depremlerde hayatını kaybetmektedir. Tarihi özelliği olan yığma yapılar genel olarak depreme dayanıklı olarak tasarlandıklarından, çoğu depremi hasarsız olarak atlatabilmektedir. Ancak daha çok bina türü konut ya da benzer amaçlar için yapılmış ve mühendislik hizmeti almadan inşa edilmiş birçok yığma yapı depremlerde hasar görmüştür.
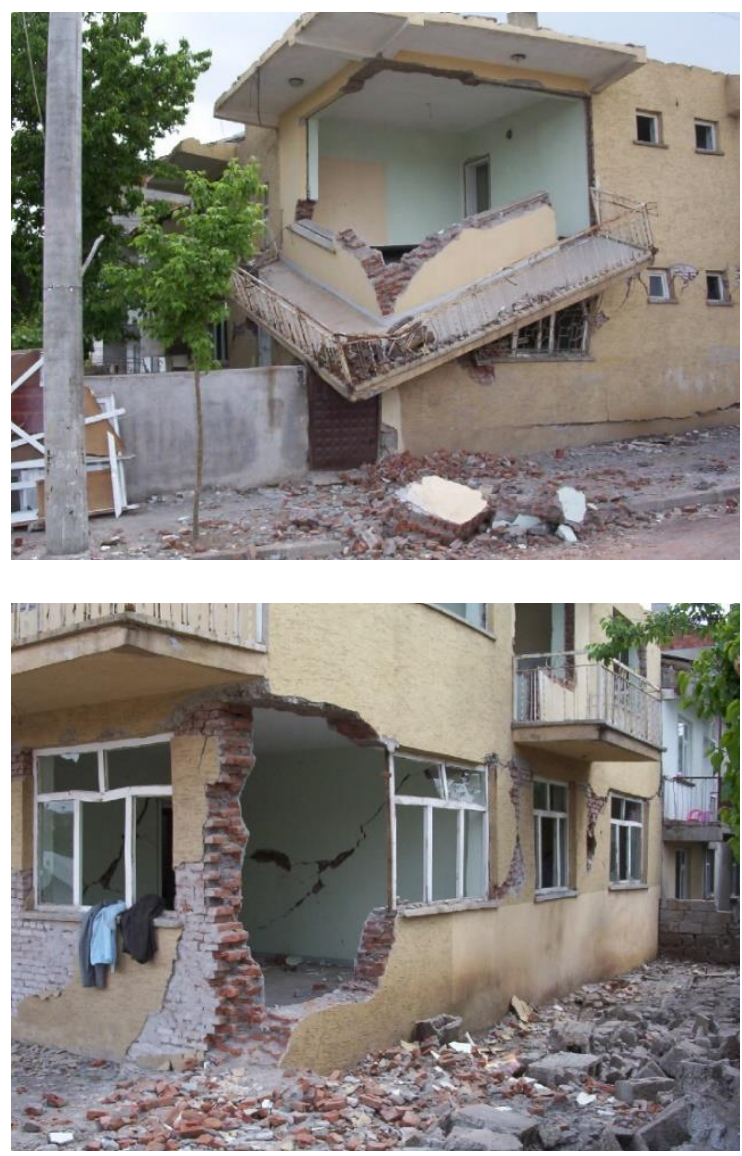

Şekil 1:

1 Mayls 2003 Bingöl depreminde hasar gören yı̆̆ma bir yapı 
Yığma binalar yerel malzemelerin bulunma durumuna bağlı olarak ülkemizin hemen her bölgesinde bulunmaktadır. Devlet İstatistik Enstitüsü 1998 yılına ait istatistiklerine göre yığma yapıların ülkedeki yapı stokuna oranı \% 70-80 gibi önemli seviyelere ulaşmaktadır (Uğuz, 2016).

Türkiye'de ciddi bir araştırma yapıldığında, bu rakamların daha da büyüyeceğini düşünmek mümkündür. Buradaki en önemli hususlardan biri, mevcut yığma yapıların deprem yönetmeliklerinde yer alan yığma yapılar yapım ilkelerine çok büyük oranda uymaması, bir diğeri de bu yapılar inşa edilirken mühendislik hizmeti alınmamasıdır.

Bu çalışmada Bingöl'de bulunduğu kabul edilen, toplam iki kattan oluşan bir yığma yapının deprem hesabı 1998, 2007 ve 2019 Deprem Yönetmelikleri esaslarına göre karşılaştırmalı olarak incelenmektedir.

\section{TÜRK DEPREM YÖNETMELIKKLERİNDE YIĞMA YAPILAR}

Bu makale kapsamında aşă̆ıdaki üç deprem yönetmeliği dikkate alınmaktadır:

1) ABYYHY-1998: Afet Bölgelerinde Yapılacak Yapılar Hakkında Yönetmelik. Bu yönetmelik 1998 yılından 2007 yılına kadar yürürlükte kalmıştır.

2) DBYBHY-2007: Deprem Bölgelerinde Yapılacak Binalar Hakkında Yönetmelik. Bu yönetmelik 2007 yılından itibaren yürürlükte olan ve 2019 yılında yerini yeni yönetmeliğe devredecek olan yönetmeliktir.

3) TBDY-2019: Türkiye Bina Deprem Yönetmeliği. Bu yönetmelik 18 Mart 2018 tarih ve 30364 sayılı resmi gazetede yayınlanmış olan ve 2019'da yürürlüğe girecek olan yönetmeliktir.

Yukarıda belirtilmiş olan yönetmeliklerin yığma yapılarla ilgili olan bölümleri incelenmiş ve her üç yönetmelikte de aynı kalan hükümler olduğu gibi, birbirinden farklı olan hükümlerin olduğu da görülmüştür. Aşağıda sadece farklı olan yönetmelik maddeleri üzerinde öz olarak bu farklılıklar sunulmaktadır.

\subsection{Deprem Bölgeleri, Etkin Yer İvmesi Katsayısı $\left(\mathrm{A}_{0}\right)$, Türkiye Deprem Tehlike Haritaları ve Spektral İvme Katsayıları $\left(S_{S}, S_{1}, S_{D S}, S_{D 1}\right)$}

1998 ve 2007 Deprem Yönetmeliklerinde 4 farklı Deprem Bölgesi tanımlanmakta ve bu deprem bölgelerine göre Etkin Yer Ívmesi Katsayıları $\left(A_{o}\right)$ verilmektedir. Bu katsayının değeri 1. derece deprem bölgesinden 4 . derece deprem bölgesine kadar, $0.4 ; 0.3 ; 0.2$ ve 0.1 şeklinde değişmektedir. 2019 Deprem Yönetmeliğinde ise artık deprem bölgeleri ve etkin yer ivmesi katsayısı tanımlanmamaktadır. Bunun yerine doğrudan binanın bulunduğu yerin koordinatları Türkiye Deprem Tehlike Haritalarında (TDTH) (2018) girilerek yer ivmesini de (PGA) kapsayacak şekilde Spektral İvme Katsayıları elde edilmektedir. Boyutsuz harita spektral ivme katsayıları, dört farklı deprem yer hareketi düzeyi için Türkiye Deprem Tehlike Haritaları kapsamında tanımlanmaktadır. Yapının koordinatlarına bağlı olarak Kısa Periyot İçin Harita Spektral İvme Katsayısı $\left(S_{S}\right)$ ve 1.0 Saniye Periyot İçin Harita Spektral İvme Katsayısı $\left(S_{I}\right)$ olmak üzere iki farklı spektral ivme katsayısı tanımlanmaktadır. TBDY-2019'a göre birbirine dik iki yatay doğrultudaki deprem etkilerinin geometrik ortalamasına karşı gelen harita spektral ivme katsayıları, belirli bir deprem yer hareketi düzeyi için referans zemin koşulu $\left[\left(V_{S}\right)_{30}=760\right.$ $\mathrm{m} / \mathrm{s}$ ] esas alınarak \%5 sönüm oranı için harita spektral ivmelerinin yerçekimi ivmesine bölünmesi ile boyutsuz katsayılar olarak tanımlanmıştır. Aşağıda açıklanan yerel zemin sınıflarına bağlı olarak bulunan yerel zemin etki katsayıları $F_{S}$ ve $F_{l}$ kullanılarak harita spektral 
ivme katsayıları $\mathrm{S}_{\mathrm{S}}$ ve $\mathrm{S}_{1}$, aşağıdaki denklemler ile Tasarım Spektral İvme Katsayıları $S_{D S}$ ve $S_{D 1}$ ’e dönüştürülür (ABYYHY, 1998; DBYBHY, 2007; TBDY, 2018).

$$
\begin{gathered}
S_{D S}=S_{S} * F_{S} \\
S_{D 1}=S_{1} * F_{1}
\end{gathered}
$$

\subsection{Yerel Zemin Sinıfları}

1998 ve 2007 deprem yönetmeliklerinde zemin grupları tanımlanmakta, zemin grupları ve en üst tabaka kalınlığına göre $\mathrm{Z1}, \mathrm{Z2}, \mathrm{Z3}$ ve Z4 olmak üzere dört farklı zemin sinıfı tanımlanmaktadır. 2019 Yönetmeliğinde ise zemin grupları bulunmamakta, doğrudan ZA, ZB, ZC, ZD, ZE ve ZF olmak üzere 6 farklı zemin sınıfı tanımlanmaktadır. Sağlamdan zayıfa doğru genel bir sınıflandırma yapıldığında 3 yönetmelikte de benzer bir gidiş vardır. Ancak 2019 yönetmeliğinde fazladan iki farklı zemin sınıfı daha tanımlanmaktadır (ABYYHY, 1998; DBYBHY, 2007; TBDY, 2018).

\subsection{Bina Kullanım Sınıfları (BKS) ve Bina Önem Katsayısı (I)}

1998 ve 2007 deprem yönetmeliklerinde sadece Bina Önem Katsaylsı tanımlanmakta, 2019 deprem yönetmeliğinde ise Bina Önem Katsayısı ile aynı tablo içinde ayrıca Bina Kullanım Sinıfi da tanımlanmaktadır. Diğer taraftan daha önce 1.4 olarak tanımlanan bina önem katsayısı artık kaldırılmış ve bu gruba giren yapılar için de Bina Önem Katsayısı 1.5 değerine yükseltilmiştir (ABYYHY, 1998; DBYBHY, 2007; TBDY, 2018).

\subsection{Deprem Yer Hareketi Düzeyleri (DD-1, DD-2, DD-3, DD-4)}

Deprem yer hareketi düzeyleri, deprem tasarım sınıflarına göre yeni yapılacak veya mevcut binalar için performans hedefleri ve uygulanacak değerlendirme/tasarım yaklaşımlarının belirlenmesinde kullanılmaktadır. 1998 ve 2007 Deprem Yönetmeliklerinde tasarım depremi altında can güvenliği performans hedefi tanımlanmıştır. Söz konusu tasarım depremi 2019 yönetmeliğinde $D D-2$ deprem düzeyine karşıllı gelmektedir. Konut türü yapılarda $D D-2$ deprem düzeyi için, can güvenliğine karşıllk için Kontrollü Hasar Performans Düzeyi tanımlanmaktadır. Dolayısıyla binaların kullanım sınıfına bağlı olarak farklı deprem düzeyleri için farklı performans düzeyleri tanımlanmaktadır. 2019 yönetmeliğinde, dört farklı deprem yer hareketi düzeyi ( $D D-1, D D-2, D D-3, D D-4)$ tanımlanmaktadır (ABYYHY, 1998; DBYBHY, 2007; TBDY, 2018).

\subsection{Deprem Tasarım Sinıfları (DTS)}

Deprem Tasarım Sinıfi (DTS) 1998 ve 2007 deprem yönetmeliklerinde tanımlanmamaktadır. DTS 2019 yönetmeliğinde tanımlanmaktadır. Bina Kullanım Sinıfları $(B K S)$ 'na ve DD-2 deprem yer hareketi düzeyi için tanımlanan Kısa Periyot Tasarım Spektral Ivme Katsayısı $\left(S_{D S}\right)$ 'na bağlı olarak, deprem etkisi altında tasarımda esas alınacak Deprem Tasarım Sinıfları ( DTS ) belirlenmektedir (ABYYHY, 1998; DBYBHY, 2007; TBDY, 2018).

\subsection{Dayanım Fazlalığı Katsayısı (D)}

1998 ve 2007 Deprem yönetmeliklerinde Dayanım Fazlalı̆̆ Katsayısı yoktur. 2019 Deprem Yönetmeliğinde betonarme, çelik, yı̆̆ma gibi tüm yapı sistemlerinde taşıyıcı sistemin özelliklerine ve süneklik düzeyine bağlı olarak Dayanım Fazlalığı Katsayısı tanımlanmaktadır. Akma dayanımı, yönetmeliklerdeki minimum koşulların uygulanması, yüklerin daha büyük seçilmesi, malzeme dayanımlarının güvenli tarafta kalma düşüncesiyle düşük tutulması gibi 
nedenlerle tasarım dayanımından daha büyük olmaktadır. Bu nedenlerden dolayı Dayanım Fazlalığ1 Katsayısı $(D)$, akma dayanımının $\left[f_{y}\left(\mu_{k}, T\right)\right]$, tasarım dayanımına $\left[f_{d}\left(\mu_{k}, T\right)\right]$ oranla fazlalığını ifade edecek şekilde tanımlanmaktadır (TBDY, 2018):

$$
D=\frac{f_{y}\left(\mu_{k}, T\right)}{f_{d}\left(\mu_{k}, T\right)}
$$

Bu denklemde

$f_{y}\left(\mu_{k}, T\right)$ : Öngörülen süneklik kapasitesi ve periyoda bağlı akma dayanımını,

$f_{d}\left(\mu_{k}, T\right)$ : Öngörülen süneklik kapasitesi ve periyoda bağlı olarak taşıyıcı sistemin sahip

olması gereken tasarım dayanımını göstermektedir.

Tasarım dayanımı, taşıma gücü yaklaşımı ile kesit tasarımı için taşıyıcı sistemin sahip olması gereken dayanım değeridir. Akma ve tasarım dayanımları yukarıdaki denklemden görüldüğü gibi süneklik kapasitesine bağlı olarak değişmektedir. Yığma binalar için Dayanım Fazlalığı Katsayısı (D) Tablo 1'den alınabilir (TBDY, 2018).

\subsection{Taşıyıcı Sistem Davranış Katsayısı ( R ) ve Deprem Yükü Azaltma Katsayısı (Ra)}

1998 ve 2007 Deprem Yönetmeliklerinde, yığma binalar için Taşıyıcı Sistem Davranış Katsayısı $(R)$ tanımlanmamakta, bunun yerine bina periyodundan bağımsız olarak, doğrudan Deprem Yükü Azaltma Katsayısı $R a\left(T_{1}\right)$ tanımlanmaktadır. 2019 Yönetmeliğinde ise Taşlyıcı Sistem Davranış Katsayısı $R$; tanımlanmakta ve yığma binalar için değeri Tablo 1'den alınmaktadır (ABYYHY, 1998; DBYBHY, 2007; TBDY, 2018).

Deprem Yükü Azaltma Katsayısının $\left(R_{a}\right)$ değeri 1998 Yönetmeliğinde 2.5 olarak, 2007 Yönetmeliğinde ise 2.0 olarak verilmektedir. 2019 Yönetmeliğinde ise Deprem Yükü Azaltma Katsayısı $\left(R_{a}\right)$, Taşıyıcı Sistem Davranış Katsayısına $(R)$, Bina Önem Katsayısına $(I)$, yapının doğal titreşim periyoduna $(T)$, Dayanım Fazlalığı Katsayısına $(D)$ ve zemin sınıfına göre dikkate alınan $T_{B}$ köşe periyoduna bağlı olarak aşağıdaki bağıntı ile hesaplanmaktadır (ABYYHY, 1998; DBYBHY, 2007; TBDY, 2018):

$$
R_{a}(T)=\left\{\begin{array}{lll}
\frac{R}{I} & \leftarrow & T>T_{B} \\
D+\left(\frac{R}{I}-D\right) \frac{T}{T_{B}} & \leftarrow & T \leq T_{B}
\end{array}\right.
$$

Yatay tasarım spektrumu köşe periyodu $\left(T_{B}\right) 1998$ ve 2007 yönetmeliklerinde zemin sınıfına bağlı olarak belirlenmektedir. 2019 Yönetmeliğinde ise tasarım spektral ivme katsayıları oranına $\left(S_{D I} / S_{D S}\right)$ bağlı olarak belirlenmektedir.

\subsection{Bina Yükseklik Sınıfları (BYS)}

Türk deprem yönetmeliklerinde Bina Yükseklik Sınıfı (BYS) ilk olarak 2019 Yönetmeliğinde tanımlanmış ve binalar yükseklikleri bakımından sekiz bina yükseklik sınıfına ayrılmıştır. Yığma binalar için dikkate alınabilecek ve izin verilen bina yükseklik sınıfları, Tablo 1 den görüldüğü gibi taşıyıcı sistem malzemesine ve taşıyıcı sistemin süneklik özelliklerine bağlı olarak verilmektedir. Tablodan görüldüğü gibi yığma binalar için izin verilen Bina Yükseklik Sınıfı taşıyıcı sisteme bağlı olarak, 7 ya da 8 olabilmektedir (TBDY, 2018). 
Amani A. Sağıroğlu S.,Doğangün A. Ö. Yığma Bina Üzerinde 1998, 2007, 2019 TDY Karşılaş. İrd.

Tablo 1. Bina taşıyıcı sistemleri için taşıyıcı sistem davranış katsayısı (R), dayanım fazlalığı katsayısı (D) ve izin verilen bina yükseklik sınıfları (BYS) (TBDY, 2018)

\begin{tabular}{|l|c|c|c|}
\hline BİNA TAŞIYICI SISTEMI & $R$ & $D$ & BYS \\
\hline E. YIĞMA BİNA TAŞIYICI SISSTEMLERI & \multicolumn{1}{|l|}{} \\
\hline E1. Süneklik Düzeyi Yüksek Taşıyıcı Sistemler \\
\hline E11. Donatılı yığma binalar & 4 & 2 & BYS $\geq 7$ \\
\hline E12. Donatılı gazbeton panel binalar & 4 & 2 & BYS $\geq 7$ \\
\hline E2. Süneklik Düzeyi Sınırlı Taşıyıcı Sistemler & 3 & 2 & BYS $=8$ \\
\hline E21. Kuşatılmış yığma binalar & 2.5 & 1.5 & BYS $=8$ \\
\hline E22. Donatısız yığma binalar
\end{tabular}

\subsection{Bina Yüksekliği $\left(\mathrm{H}_{\mathrm{N}}\right)$}

1998 ve 2007 Yönetmeliklerinde bina yüksekliği yerine yığma binalar için deprem bölgelerine göre kat sayısına ilişkin sınırlamalar getirilmiştir. 2019 Yönetmeliğinde ise kat sayısının yanında bina yüksekliğine ilişkin de sınırlamalar getirilmiştir. Bu yönetmeliğe göre, yığma binalar için, hesap ve tasarımı yapılan binanın yüksekliği; Bina Yükseklik Sınıfına (BYS) ve Deprem Tasarım Sınıflarına (DTS) bağlı olarak Tablo 2'de belirtilen değerler arasında olmalıdır (TBDY, 2018).

Tablo 2. Bina yükseklik sınıfları ve deprem tasarım sınıflarına göre tanımlanan bina yükseklik aralıkları (TBDY, 2018)

\begin{tabular}{|c|c|c|c|}
\hline \multirow{2}{*}{$\begin{array}{c}\text { BINA } \\
\text { YÜKSEKLIK } \\
\text { SINIFI }\end{array}$} & \multicolumn{2}{|c|}{$\begin{array}{c}\text { Bina Yükseklik Sinıfları ve Deprem Tasarım Sınıflarına Göre Tanımlanan } \\
\text { Bina Yükseklik Aralıkları }[\mathrm{m}]\end{array}$} \\
\cline { 2 - 3 } & DTS $=1,1 \mathrm{a}, 2,2 \mathrm{a}$ & DTS $=3,3 \mathrm{a}$ & DTS $=4,4 \mathrm{a}$ \\
\hline BYS $=7$ & $7 \mathrm{~m}<H_{N}<10.5 \mathrm{~m}$ & $10.5 \mathrm{~m}<H_{N}<17.5 \mathrm{~m}$ \\
\hline BYS $=8$ & $H_{N}<7 \mathrm{~m}$ & $H_{N}<10.5 \mathrm{~m}$ \\
\hline
\end{tabular}

\subsection{Yatay Elastik Tasarım Spektral İvmeleri $\left(\mathrm{S}(\mathrm{T}), \mathrm{S}_{\mathrm{ae}}(\mathrm{T})\right)$}

Yığma yapılar için 2019 Yönetmeliğinin getirdiği en önemli değişikliklerden biri elastik tasarım spektral ivmeleri noktasında olmuştur. 1998 ve 2007 Yönetmeliklerinde yığma yapılar için deprem kuvvetlerinin hesabında kullanılacak olan spektrum katsayıs $S(T)$ yap1 periyodundan ve zemin sınıfından bağımsız olarak sabit $S(T)=2.5$ olarak öngörülmekte idi. 2019 Yönetmeliğinde ise yapı periyoduna ve zemin sınıfına bağlı olarak Yatay Elastik Tasarım Spektral İvmesi $S_{a e}(T)$ Şekil 2'de verilen spektrum eğrisinden hesaplanmaktadır (ABYYHY, 1998; DBYBHY, 2007; TBDY, 2018). 


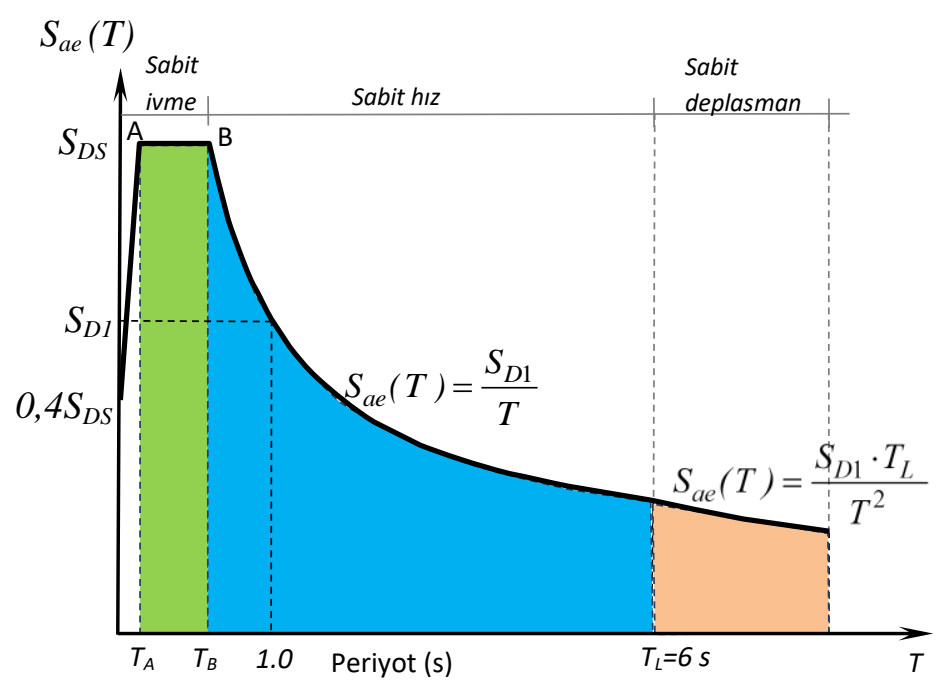

Şekil 2:

Elastik tasarim yatay ivme spektrumu

\section{3. ÖRNEK OLARAK SEÇILEN YIĞMA YAPI}

Bu çalışmada Bingöl'de bulunduğu kabul edilen, toplam iki kattan oluşan bir yığma yapı örnek olarak seçilmiştir. İncelenen Örnek kâgir yapı $100.44 \mathrm{~m}^{2}$ 'lik bir alana oturmaktadır. Şekil 3'de incelenen yapının planı gösterilmektedir. İncelenen binaya ait genel özellikler ve binanın deprem hesabı için dikkate alınan parametreler Tablo 3'de verilmiştir. Bu çalışmada ABYBHY1998; DBYBHY-2007 ve TBDY-2019 Deprem Yönetmeliklerine göre örnek binanın deprem hesabı gerçekleştirilmiş, hesaplanan taban kesme kuvvetleri ve katlara etkiyen eşdeğer deprem yükleri karşılaştırılmıştır.

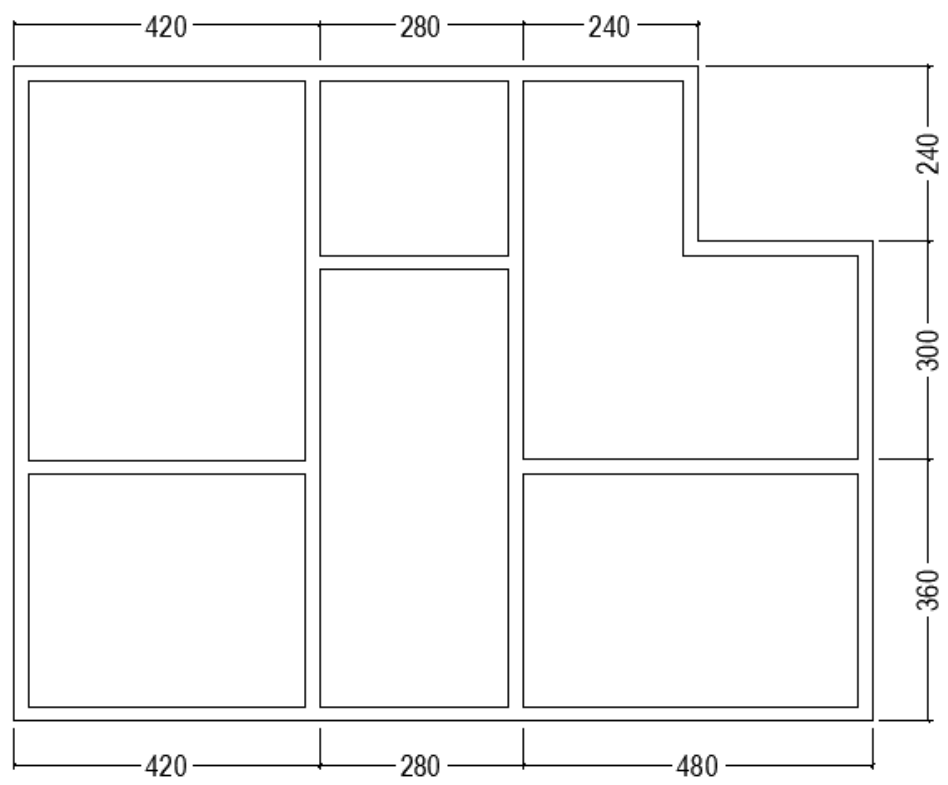

Şekil 3:

Örnek yığma yapının plan görünüşü (Erden, 2004) 
Amani A. Sağıroğlu S.,Doğangün A. Ö. Yığma Bina Üzerinde 1998, 2007, 2019 TDY Karşılaş. İrd.

Tablo 3. Binanın deprem hesabı için dikkate alınan parametreler (ABYYHY, 1998; DBYBHY, 2007; TBDY, 2018).

\begin{tabular}{|c|c|c|c|}
\hline Parametre & $\begin{array}{c}\text { ABYYHY- } \\
1998 \\
\end{array}$ & $\begin{array}{l}\text { DBYBHY- } \\
2007 \\
\end{array}$ & TBDY-2019 \\
\hline Yapının Bulunduğu İl/ İlçe & \multicolumn{3}{|c|}{ Bingöl-Merkez } \\
\hline Deprem Bölgesi & 1 & 1 & $\begin{array}{c}\text { Koordinat: Enlem :38.882768 } \\
\text { Boylam: } 40.509663\end{array}$ \\
\hline Deprem Yer Hareketi Düzeyi & - & - & DD-2 \\
\hline $\begin{array}{l}\text { Etkin Yer İvmesi Katsayıs1 }\left(\mathrm{A}_{0}\right) \text {, } \\
\text { Maksimum Yer İvmesi (PGA) }\end{array}$ & $\mathrm{A}_{0}=0.40 \mathrm{~g}$ & $\mathrm{~A}_{0}=0.40 \mathrm{~g}$ & $\begin{array}{c}\text { Türkiye Deprem Tehlike } \\
\text { Haritalarından: PGA }=0.655 \mathrm{~g}\end{array}$ \\
\hline Yerel Zemin Sinıfi & $\mathrm{Z} 1$ & $\mathrm{Z} 1$ & ZA \\
\hline $\begin{array}{l}\text { Spektrum İvme Katsayıs } S(T) \text {, } \\
S_{\mathrm{ae}}(\mathrm{T})\end{array}$ & 2.5 (sabit) & 2.5 (sabit) & Hesap sonucu 1.286 \\
\hline $\begin{array}{l}\text { Kisa periyot harita spektral ivme } \\
\text { katsayıs } S_{S}\end{array}$ & - & - & $\begin{array}{l}\text { Türkiye Deprem Tehlike } \\
\text { Haritalarından: } 1.608\end{array}$ \\
\hline $\begin{array}{l}1.0 \mathrm{~s} \text { periyot harita spektral ivme } \\
\text { katsayis1 } S_{I}\end{array}$ & - & - & $\begin{array}{l}\text { Türkiye Deprem Tehlike } \\
\text { Haritalarından: } 0.421\end{array}$ \\
\hline $\begin{array}{l}\text { Kisa periyot tasarım spektral ivme } \\
\text { katsayıs } S_{D S}\end{array}$ & - & - & Hesap sonucu 1.286 \\
\hline $\begin{array}{l}1 \text { s periyot tasarim spektral ivme } \\
\text { katsayis1 } S_{D I}\end{array}$ & - & - & Hesap sonucu 0.337 \\
\hline Bina Kullanım Sınıfları ( BKS ) & - & - & 3 \\
\hline Bina Önem Katsayısı ( I ) & 1 & 1 & 1 \\
\hline Dayanım Fazlalı̆̆ı Katsayısı $(D)$ & - & - & 1.5 \\
\hline Deprem Tasarım Sinıfları ( DTS ) & - & - & $S_{D S}>0.75$ olduğundan 1 \\
\hline Bina Yükseklik Sınıfları ( BYS ) & - & - & 8 \\
\hline $\begin{array}{l}\text { Taşıyıcı Sistem Davranış Katsayısı } \\
(R)\end{array}$ & - & - & 2.5 \\
\hline $\begin{array}{l}\text { Deprem Yükü Azaltma Katsayısı } \\
\left(R_{a}\right)\end{array}$ & 2.5 (sabit) & 2.0 (sabit) & Hesap sonucu: 1.8129 \\
\hline Bina & \multicolumn{3}{|c|}{ Donatısız yı̆̆ma bina } \\
\hline Bina Yüksekliği $\left(H_{N}\right)$ & \multicolumn{3}{|c|}{$5.4 \mathrm{~m}$} \\
\hline Döşeme Alanı & \multicolumn{3}{|c|}{$100.44 \mathrm{~m}^{2}$} \\
\hline Duvar Kalınlı̆̆ 1 & \multicolumn{3}{|c|}{$30 \mathrm{~cm}$} \\
\hline Bina Hareketli Yükü & \multicolumn{3}{|c|}{$2 \mathrm{kN} / \mathrm{m}^{2}$} \\
\hline Lento Boyutu & \multicolumn{3}{|c|}{$30 \mathrm{~cm} \times 30 \mathrm{~cm}$} \\
\hline Kat Yüksekliği & \multicolumn{3}{|c|}{$270 \mathrm{~cm}$} \\
\hline Kat Adedi & \multicolumn{3}{|c|}{2} \\
\hline Tuğla Birim Ağırlığ & \multicolumn{3}{|c|}{$15 \mathrm{kN} / \mathrm{m}^{3}$} \\
\hline
\end{tabular}

$\mathrm{Bu}$ çalışmada kalıcı ( sabit) yükler $G_{i}(\mathrm{kN})$ malzeme ağırlıklarından, hareketli yükler $Q_{i}$ $(\mathrm{kN})$ ise TS 498 den alınarak Tablo 4 de görüldüğü gibi dikkate alınmaktadır. Kat ağırlıkları $w_{i}=G_{i}+n^{*} Q_{i}$ bağıntısı ile belirlenmektedir. Bu bağıntıda $n$ hareketli yük katılım katsayısını göstermekte olup konut türü yapı için 0.3 olarak dikkate alınmıştır.

Tablo 4. Bina için dikkate alınan düşey yükler, kat ağırlıkları ve kütleleri

\begin{tabular}{|c|c|c|c|c|}
\hline \multirow{2}{*}{ Kat No } & $\begin{array}{c}\text { Kat } \\
\text { Kalıcı Yük }\end{array}$ & $\begin{array}{c}\text { Kat } \\
\text { Hareketli Yük }\end{array}$ & $\begin{array}{c}\text { Kat } \\
\text { Ă̆ırlı̆̆ }\end{array}$ & $\begin{array}{c}\text { Kat } \\
\text { Kütlesi }\end{array}$ \\
\cline { 2 - 5 } & $G_{i}(\mathrm{kN})$ & $Q_{i}(\mathrm{kN})$ & $w_{i}(\mathrm{kN})$ & $m_{i}(\mathrm{t})$ \\
\hline 2.Kat & 1104.22 & 200.88 & 1164.48 & 118.7 \\
\hline 1.Kat & 1104.22 & 200.88 & 1164.48 & 118.7 \\
\hline Toplam & & & $\mathrm{W}=2328.97$ & $m_{t}=237.4$ \\
\hline
\end{tabular}


Deprem yönetmeliklerinde Eşdeğer Deprem Yükü Yönteminin uygulandığ1 tüm binalarda göz önüne alınan deprem doğrultusunda binanın hâkim doğal titreşim periyodu $\left(T_{l}\right)$ için aşağıdaki denklem önerilmektedir:

$$
T_{1}=2 \pi \sqrt{\frac{\sum_{i=1}^{N} m_{i} d_{f i}{ }^{2}}{\sum_{i=1}^{N} F_{f i} d_{f i}}}
$$

Bu bağıntıda gerekli olan fiktif yükler $\left(F_{f i}\right)$ yapının kat kütle merkezlerine etkitilerek kat ötelemeleri hesaplanabilmektedir. Bunların SAP2000 (2017) programı ile hesaplanan değerleri aşağıda Tablo 5 de sunulmaktadır:

Tablo 5. Periyot hesabında gerekli parametreler

\begin{tabular}{|c|c|c|c|c|c|c|}
\hline \multirow{2}{*}{ Kat No } & Kat ağırlığ & Kat kütlesi & \multirow{2}{*}{$H_{i}(\mathrm{~m})$} & \multirow{2}{*}{$\mathrm{w}_{\mathrm{i}} * H_{i}(\mathrm{kNm})$} & $F_{f i}(k N)$ & \multirow{2}{*}{$d_{f i}(m)$} \\
\cline { 2 - 3 } & $w_{i}(\mathrm{kN})$ & $m_{i}(t)$ & & 6288.21 & 0.667 & $7.7529 \mathrm{E}-09$ \\
\hline 2.Kat & 1164.48 & 118.70 & 5.4 & 3144.11 & 0.333 & $4.9691 \mathrm{E}-07$ \\
\hline 1.Kat & 1164.48 & 118.70 & 2.7 & 3 \\
\hline
\end{tabular}

Hesaplanan parametreler periyot bağıntısında yerine yazılırsa, $T_{l}=0.082 \mathrm{~s}$ olarak belirlenir.

\subsection{ABYYHY-1998 Yönetmeliğine Göre Taban Kesme Kuvveti}

1998 Yönetmeliğine göre binaya etkiyecek toplam deprem yüküne karş1lık gelen taban kesme kuvveti $\left(V_{t}\right)$ aşağıdaki şekilde hesaplanmaktadır:

$V_{t}=\frac{A_{o} * I * S\left(T_{1}\right) * W}{R_{a}} \geq 0.10 A_{o} I W$

$V_{t}=\frac{0.40 * 1 * 2.5 * 2328.97}{2.50} \geq 0.10 * 0.4 * 1 * 2328.97$

$V_{t}=931.59 \mathrm{kN} \geq 93.16 \mathrm{kN} \quad \rightarrow \quad V_{t}=931.59 \mathrm{kN}$

Yukarıdaki formülde $W$ binanın toplam ağırlığını temsil etmektedir ve Tablo 4'den alınmıştır. Diğer değişkenlere ait değerler Tablo 3'de verilmiştir.

1998 Yönetmeliğine göre $\mathrm{H}_{\mathrm{N}}>25 \mathrm{~m}$ için binanın N'inci katına (tepesine) etkiyen ek eşdeğer deprem yükü, $\Delta \mathrm{F}_{\mathrm{N}}$ 'in değeri birinci doğal titreşim periyodu $T_{1}$ 'e bağlı olarak aşağıdaki denklemle belirlenebilir.

$$
\Delta F_{N}=0.07 * T_{1} * V_{t} \leq 0.20 * V_{t}
$$

Ancak yönetmelikte $\mathrm{H}_{\mathrm{N}} \leq 25 \mathrm{~m}$ için $\Delta \mathrm{F}_{\mathrm{N}}=0$ alınması öngörülmüştür. Örnek binanın yüksekliği $25 \mathrm{~m}$ 'den küçük olduğu için $\Delta \mathrm{F}_{\mathrm{N}}$ hesaplanmamıştır. Kat seviyelerine etkiyen deprem yükü çalışmada dikkate alınan üç deprem yönetmeliği için de aşağıdaki bağıntı yardımıyla belirlenmektedir. 


$$
F_{i}=\left(V_{t}-\Delta F_{N}\right) \frac{w_{i} \cdot H_{i}}{\sum_{j=1}^{N} w_{j} \cdot H_{j}}
$$

Bu denklemde daha önce tanımlanmayan değişkenler aşağıda verilmiştir.

$F_{i}$ : i. kat seviyesine etkiyen eşdeğer deprem yükünü,

$w_{i}$ ve $w_{j}:$ i. ve j. kat ağılıklarını,

$H_{i}$ ve $H_{j}$ : i. ve j. katın temel üstünden itibaren ölçülen yüksekliğini,

$N$ kat sayısını göstermektedir.

1998 Yönetmeliğine göre kat seviyelerine etkiyen deprem yükü ve taban kesme kuvveti Tablo 6 da diğer yönetmelik sonuçlarıyla birlikte verilmektedir.

\subsection{DBYBHY-2007 Yönetmeliğine Göre Taban Kesme Kuvveti}

2007 Yönetmeliğine göre binaya etkiyecek toplam deprem yüküne karşıllk gelen taban kesme kuvveti aşağıdaki şekilde hesaplanmaktadır:

$$
\begin{aligned}
& V_{t}=\frac{W * A_{o} * I * S\left(T_{1}\right)}{R_{a}\left(T_{1}\right)} \geq 0.10 * A_{o} * I * W \\
& V_{t}=\frac{2328.97 * 0.4 * 1 * 2.5}{2} \geq 0.10 * 0.40 * 1 * 2328.97 \\
& V_{t}=1164.49 \geq 93.16 \mathrm{kN} \quad \rightarrow \quad V_{t}=1164.49 \mathrm{kN}
\end{aligned}
$$

2007 Yönetmeliğine göre binanın N'inci katına (tepesine) etkiyen ek eşdeğer deprem yükü $\Delta \mathrm{F}_{\mathrm{N}}{ }^{\prime}$ in değeri aşağıdaki denklemle belirlenebilir.

$$
\begin{aligned}
& \Delta F_{N}=0.0075 * N * V_{t} \\
& \Delta F_{N}=0.0075 * 2 * 1164.49=17.47 \mathrm{kN}
\end{aligned}
$$

2007 Yönetmeliğine göre kat seviyelerine etkiyen deprem yükü ve taban kesme kuvveti Tablo 6 da diğer yönetmelik sonuçlarıyla birlikte verilmektedir

\subsection{TBDY-2019 Yönetmeliğine Göre Taban Kesme Kuvveti}

2019 Yönetmeliğine göre binaya etkiyecek (X doğrultusundaki) toplam deprem yüküne karşılık gelen taban kesme kuvveti $V_{t E}^{(X)}$, aşağıdaki bağıntı ile belirlenmektedir:

$$
V_{t E}^{(X)}=m_{t} \times S_{a R}\left(T_{P}^{(X)}\right) \geq 0.04 \times m_{t} \times I \times S_{D S} \times g
$$

$\mathrm{Bu}$ denklemde:

$m_{t}$ : binanın bodrum katlarının üstündeki üst bölümünün toplam kütlesini,

$S_{a R}\left(T_{P}^{(X)}\right)$ : göz önüne alınan $(\mathrm{X})$ deprem doğrultusunda, binanın hâkim doğal titreşim periyodu $\left(T_{P}^{(X)}\right)$ göz önüne alınarak hesaplanan Azaltılmış Tasarım Spektral İvmesini, 
$g$ : yerçekimi ivmesini göstermektedir. Diğer değişkenler önceki bölümlerde tanımlanmıştır.

Binanın toplam kütlesi Tablo 4'den $m_{t}=237.4 \mathrm{t}$ olarak alınmıştır. 2019 TBDY'de Azaltılmış Tasarım Spektral İvmesi aşağıdaki bağıntı ile verilmiştir.

$$
S_{a R}(T)=\frac{S_{a e}(T)}{R_{a}(T)}
$$

2019 TBDY'ne göre yatay elastik tasarım spektral ivmesi $S_{a e}(T)$ aşağıdaki bağıntılardan uygun olanı ile bulunabilir.

$$
\begin{aligned}
S_{a e}(T)=\left(0.4+0.6 \frac{T}{T_{A}}\right) S_{D S} & \left(0 \leq T \leq T_{A}\right) \\
S_{a e}(T)=S_{D S} & \left(T_{A} \leq T \leq T_{B}\right) \\
S_{a e}(T)=\frac{S_{D 1}}{T} & \left(T_{B} \leq T \leq T_{L}\right) \\
S_{a e}(T)=\frac{S_{D 1} T_{L}}{T^{2}} & \left(T_{L} \leq T\right)
\end{aligned}
$$

Bu denklemlerde daha önce tanımlanmamış olan değişkenlerden:

$T_{A}$ ve $T_{B}$ : yatay elastik tasarım ivme spektrumu köşe periyotlarını,

$T_{L}$ : yatay elastik tasarım spektrumunda sabit yerdeğiştirme bölgesine geçiş periyodunu göstermektedir.

Yatay elastik tasarım ivme spektrumu köşe periyotları $T_{A}$ ve $T_{B}$ aşağıdaki eşitliklerle bulunabilir.

$$
T_{A}=0.2 \frac{S_{D 1}}{S_{D S}} \quad T_{B}=\frac{S_{D 1}}{S_{D S}}
$$

Göz önüne alınan yapıya ait $S_{D I}$ ve $S_{D S}$ değerleri Tablo 3'de verilmiști. Yukarıdaki eşitliklerde yerlerine yazılırsa:

$$
T_{A}=0.2 \frac{0.337}{1.286}=0.0524 \mathrm{~s} \text { ve } T_{B}=\frac{0.337}{1.286}=0.2621 \mathrm{~s} \text { olarak bulunur. }
$$

Binanın hâkim doğal titreşim periyodu $T_{A}$ ve $T_{B}$ arasında olduğu için $\left(T_{A}=0.0524 \mathrm{~s} \leq\right.$ $\left.T=0.082 s \leq T_{B}=0.2621 s\right)$ :

$$
S_{a e}(T)=S_{D S}=1.286 \mathrm{~g}=1.286 \times 9.81=12.616 \mathrm{~m} / \mathrm{s}^{2} \text { olarak bulunur. }
$$

İncelenen yapı donatısız yığma bina olduğu için Taşıyıcı Sistem Davranış Katsayısı (R) ve Dayanım Fazlalığı Katsayısı (D)'nin değerlerinin sırasıyla 2.5 ve 1.5 olduğu Tablo 1'de görülebilir.

Deprem Yükü Azaltma Katsayısı $R_{a}(T)$ 'nin hesabında $T=0.082 \mathrm{~s}<T_{B}=0.262 \mathrm{~s}$ olduğu için önceki bölümlerde $R_{a}(T)$ için verilen eşitliklerden uygun olan kullanılırsa: 
$R_{a}(T)=D+\left(\frac{R}{I}-D\right) \frac{T}{T_{B}}=1.5+\left(\frac{2.5}{1}-1.5\right) \frac{0.082}{0.2621}=1.8129$ olarak bulunur.

Yatay Deprem Etkisi Altında Azaltılmış Tasarım İvme Spektrumu değeri

$\mathrm{S}_{\mathrm{aR}}(\mathrm{T})=\frac{\mathrm{S}_{\mathrm{ae}}(\mathrm{T})}{\mathrm{R}_{\mathrm{a}}(\mathrm{T})}=\frac{12.616}{1.8129}=6.96 \mathrm{~m} / \mathrm{s}^{2}$ olarak elde edilir.

Binanın tümüne etkiyen toplam eşdeğer deprem yükü (taban kesme kuvveti)

$$
\begin{aligned}
& V_{t E}^{(X)}=m_{t} * S_{a R}\left(T_{P}^{(X)}\right) \geq 0.04 * m_{t} * I * S_{D S} * g \\
& V_{t E}^{(X)}=237.4 * 6.96 \geq 0.04 * 237.4 * 1 * 1.286 * 9.81 \\
& V_{t E}^{(X)}=1652.3 \mathrm{kN} \geq 119.80 \mathrm{kN} \\
& V_{t E}^{(X)}=1652.3 \mathrm{kN} \text { olarak bulunur. }
\end{aligned}
$$

En üst kata etkiyen ek yük aşağıdaki bağıntı ile belirlenmektedir.

$$
\Delta F_{N E}^{(X)}=0.0075 * N * V_{t E}^{(X)}=0.0075 * 2 * 1652.3=24.78 k N
$$

2019 Yönetmeliğine göre kat seviyelerine etkiyen deprem yükü ve taban kesme kuvveti Tablo 6'da diğer yönetmelik sonuçlarıyla birlikte verilmektedir

\section{BULGULAR VE SONUÇLAR}

Yığma yapılar ilk çağlardan itibaren yapılmış ve bugün de kullanılan yapım tekniklerinden biri olduğundan deprem bölgelerinde bulunmaları halinde deprem yönetmeliklerinin konusu olmaktadır. Ülkemiz Dünya'nın en aktif deprem kuşaklarından birinde bulunduğundan yığma yapıların hesap ve tasarımı yönetmeliklerin güncellemesi aşamasında dikkate alınmaktadır. Ülkemizde uygulanmış olan en son iki deprem yönetmeliği (ABYYHY-1998 ve DBYBHY2007) ile Mart 2018'de Resmi Gazetede yayınlanmış ve 2019'da yürürlüğe girecek olan TBDY2019 Yönetmeliği bu makalede dikkate alınmıştır.

TBDY-2019 yığma yapılar konusunda diğer eski deprem yönetmeliklerine göre çok önemli farklılıklar getirmektedir. Bunların başında;

(1)Deprem bölgesinin artık kaldırılmış olması, bunun yerine doğrudan Türkiye Deprem Tehlike Haritasında binanın koordinatlanı girilerek deprem parametrelerinin alınması,

(2) Yığma yapılar için zemin sınıfından bağımsız olarak hesap ve tasarım yapılmakta iken artık zemin sınıflarının da dikkate alınması,

(3) Tasarım spektrumunda yığma yapılar için sabit 2.5 değeri dikkate alınmakta iken, artık bina periyoduna ve zemin sınıfina göre farklı değerlerin hesap sonucu elde edilmesi,

(4) Periyottan bağımsız olarak sabit bir deprem yükü azaltma katsayısı kullanılmakta iken, yeni yönetmelikte periyot $(\mathrm{T})$, dayanım fazlalığı katsayıSı $(\mathrm{D})$ ve taşıyıcı sistem davranış katsayısına $(\mathrm{R})$ bağlı olarak Deprem Yükü Azaltma katsayısı $\left(\mathrm{R}_{\mathrm{a}}\right)$ tanımlanması sayılabilir.

Çalışmada dikkate alınan üç yönetmeliğe göre yapının deprem hesabı gerçekleştirilmiş ve Tablo 6'da görülen taban kesme kuvveti ve kat seviyelerine etkiyen deprem yatay yükleri 
belirlenmiştir. $\mathrm{Bu}$ tablodan görüldüğü gibi her üç yönetmelik için de farklı taban kesme kuvvetleri ve buna bağlı olarak da kat seviyelerine etkiyen farklı yatay yükler elde edilmiştir. En küçük değerleri ABYYHY-1998 Yönetmeliği en büyük değerleri ise TBDY-2019 Yönetmeliği vermiştir. Hesaplanan değerin büyüklüğü açısından bir karşılaştırma yapılırsa TBDY-2019 Yönetmeliği ABYYHY-1998 e göre \%77, DBYBHY-2007 e göre ise \%42 daha büyük taban kesme kuvveti vermiştir. Burada bu oranların çalışmada örnek alınan bina için olduğu unutulmamalidır.

Tablo 6. Dikkate alınan üç yönetmeliğe göre hesaplanmış kat seviyelerine etkiyen deprem yükü ve taban kesme kuvveti değerleri

\begin{tabular}{|l|l|c|c|c|}
\hline \multicolumn{2}{|l|}{ DEPREM KUVVETLERI } & $\begin{array}{c}\text { ABYYHY- } \\
\mathbf{1 9 9 8}\end{array}$ & $\begin{array}{c}\text { DBYBHY- } \\
\mathbf{2 0 0 7}\end{array}$ & TBDY-2019 \\
\hline \multirow{2}{*}{$\begin{array}{l}\text { Kat seviyelerine etkiyen } \\
\text { deprem yükleri }(\mathrm{kN})\end{array}$} & $\begin{array}{l}2 . \text { kat }\left(F_{2}+\Delta F_{N}\right. \\
\text { ) }\end{array}$ & 621.06 & 782.15 & 1109.79 \\
\cline { 2 - 5 } & 1. kat $\left(F_{l}\right)$ & 310.53 & 382.34 & 542.51 \\
\hline Taban kesme kuvveti, $V_{t},(\mathrm{kN})$ & 931.59 & 1164.49 & 1652.3 \\
\hline
\end{tabular}

\section{KAYNAKLAR}

1. ABYYHY, (1998). Afet Bölgelerinde Yapılacak Yapılar Hakkında Yönetmelik, Bayındırlık ve İskân Bakanlığı, Ankara

2. DBYBHY, (2007). Deprem Bölgelerinde Yapılacak Binalar Hakkında Yönetmelik, Bayındırlık ve İskân Bakanlığı, Ankara.

3. Erden, G. (2004), Donatısız ve sarılmış yığma yapıların deprem davranışlarının incelenmesi. Yüksek Lisans Tezi, KTÜ, Fen Bilimleri Enstitüsü, Trabzon, 133 sayfa

4. SAP2000, (2017). Structural Analysis Program, CSI, Berkeley, USA.

5. TBDY, (2018). Türkiye Bina Deprem Yönetmeliği, Türkiye Cumhuriyeti Başbakanlık Afet ve Acil Durum Yönetimi Başkanlığı, Ankara.

6. TDTH (2018). Türkiye Deprem Tehlike Haritaları (https://tdth.afad.gov.tr), Türkiye Cumhuriyeti Başbakanlık Afet ve Acil Durum Yönetimi Başkanlığı, Ankara.

7. Uğuz, S., (2016). Tarihi Yığma Bir Yapının Deprem Güvenlik Analizi, Tarihi Konya-Gazi Lisesi (Darü’l Muallim). Yüksek Lisans Tezi, Selçuk Üniversitesi, Fen Bilimleri Enstitüsü, İnşaat Mühendisliği Anabilim Dalı, Konya. 
